\title{
Shaping Efficiency of WaveOne Gold and One Curve in Simulated J-Shaped Root Canals
}

\author{
Ayfer Atav Ates*, Burçin Arıcan \\ Department of Endodontics, Faculty of Dentistry, Istanbul Okan University, Istanbul, Turkey
}

\begin{abstract}
To evaluate the shaping efficiency of WaveOne Gold (WOG; Dentsply Sirona, Ballaigues, Switzerland) and One Curve (OC; Micro-Mega, Besancon, France) in J-shaped resin blocks.

Forty simulated J-shaped root canals with $0.15 \mathrm{~mm}$ apical diameters and $2 \%$ taper were divided into two groups $(\mathrm{n}=20)$ as follows; WOGG/WOG (25.07) group (glide path was created with WaveOne Gold Glider) and OneG/OC (25.06) (glide path was created with One G) group. The pre- and post-instrumentation images were taken, and the transportation value (TV), centering ability (CA) and the total amount of resin removed (TRR) were calculated by using the superimposition of the images. These parameters calculated with Image J Software Program based on 18 reference points with 1 -mm intervals of the canal. The data were analyzed with Kruskal-Wallis and than Dunn's multiple comparison tests. The significance level was set at $P \leq .05$

There was no statistically significant difference among OG/OC and WOG/WOGG groups' apical (points 1-3), middle (points 4-6), and coronal (points 7-9) sections in terms of both TV and TRR. The centering ability of the instruments was decreased in the curvature part (middle section) of the canals. While WOG group showed better centering ability at points 6- 7, OC group exhibited better result at point 2.

It was shown that WaveOne Gold and One Curve, which are single-file systems, could be used safely in J-shaped root canals with their glide path files.
\end{abstract}

Keywords: Glide path, OneCurve, Rotary instruments, Resin blocks, WaveOne Gold

\section{Introduction}

Single-file systems have been widely used in root canal preparation since it was first produced in 2008 (1). These files have several advantages such as being time-saving, prevention of crosscontamination among patients, fewer complications due to file-separation and being cost-effective (2-4).

One Curve (OC) is a single-file system that works in a continuous rotation movement. It has several tip diameters $(0.25,0.35$ and 0.40$)$ and tapers $(4 \%$ and $6 \%$ ). It is manufactured from C-Wire by using proprietary heat treatment in 2017 . This alloy has two main steps: an initial electropolishing and a subsequent heat-treatment which provide its advanced properties (5). It reduces treatment time and allows irrigation more time during root canal therapy. It is a hyper-flexible instrument through its control memory technology (6). One G (OG) is a glide path file that is a compliment for One Curve system. It has $0.14 \mathrm{~mm}$ tip diameter and $3 \%$ constant taper. It has an asymmetrical crosssection with a variable pitch between each cutting edge, which limits its screwing effect. According to the manufacturer claims, it respects and maintains original root canal anatomy and could be used in thin and curved root canals safely (7).

WaveOne Gold (WOG) is a single-file technique. Its primary file which is mostly recommended for most of the canals has an optimized tip (0.25) with a variable taper (7\%) (8). According to the manufacturer claims, when compared with standard rotary instruments, its screwing effect was reduced, and flexibility was enhanced thanks to its gold technology (8). WaveOne Gold Glider (WOGG) is the glide path file of this system, which has 0.15 tip size with a progressively increasing taper from $2 \%$ to $6 \%$. This is a single reciprocating file with semi-active tip and a parallelogram-shaped cross section (9).

Single file systems are generally preferred by practitioners because of features such as time saving and ease of use (10). However, to our knowledge, there is not any study about the shaping ability of these new and popular single-file systems. The aim of this study was to investigate the shaping ability of reciprocating (WOG) and rotating (OC) single-file systems when they used 


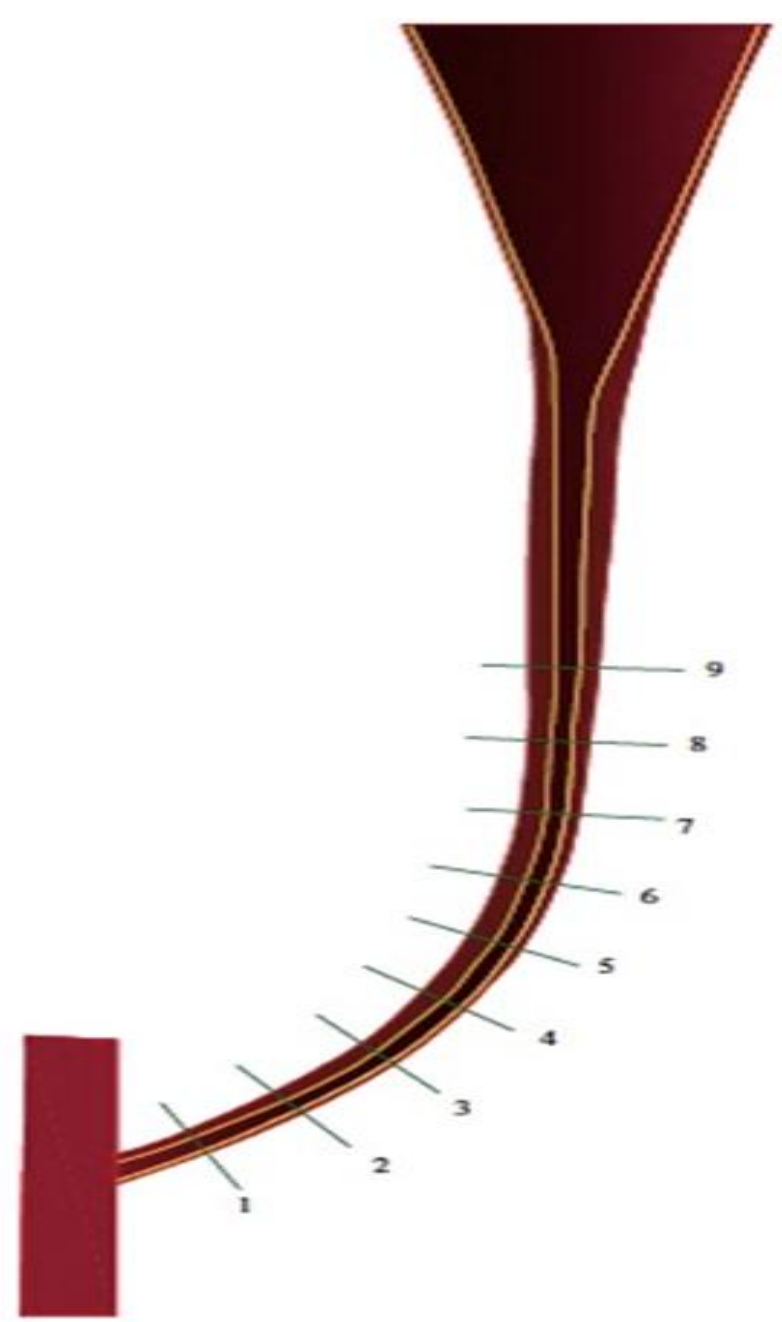

Fig. 1. Schematic presentation of lines which were drawn at $1 \mathrm{~mm}$ intervals perpendicular to the middle axis of the canal

with their own glide path files. The null hypothesis tested in this study was; there would be no difference among the shaping ability of WOG and $\mathrm{OC}$ in acrylic resin blocks.

\section{Material and Methods}

Simulated canals: Forty endo-training resin blocks with J-shaped canals that have 0.02 taper, $10 \mathrm{~mm}$ radius of curvature, $70^{\circ}$ angle of curvature, and $16 \mathrm{~mm}$ working length were used in this study. The canal openings of the simulated canals were controlled with the \# $10 \mathrm{~K}$ file. The samples were stained with black ink (Winsor \& Newton, Colart Tianjin Art Materials, Tianjin, China). The images of the samples before the instrumentation were taken with a photo camera (Canon EOS 700 D, Canon Incorporated, Tokyo, Japan) which was adapted to a standard setup that has a metal holder for the stabilization of the blocks. Then all

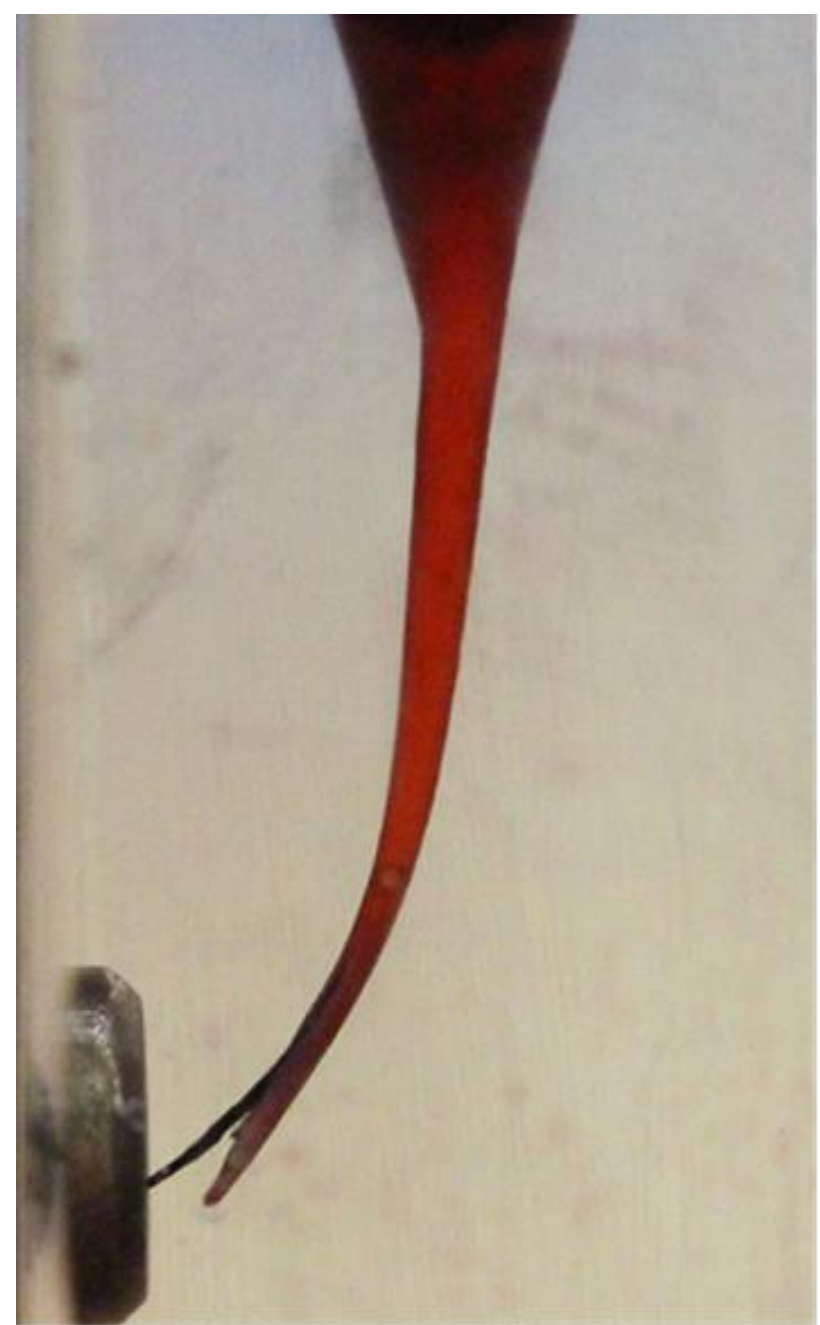

Fig. 2. The black ink represents the initial canal shape. The area with red ink shows the ledge formation occurred in OC group

the samples were randomly divided into two experimental groups;

Experimental groups and shaping procedures: Group $1(n=20)$ : According to the manufacturer instructions, OG (14/.03) was used as a glide path in continuous rotation at $300 \mathrm{rpm}$ and $1.2 \mathrm{Ncm}$ torque. The patency was again checked by the \# $15 \mathrm{~K}$ file. And then shaping of the root canals was performed with OC (25/.06) at $300 \mathrm{rpm}$ and 2.5 $\mathrm{Ncm}$ torque. The root canals were irrigated with distilled water during the instrumentation.

Group $2(n=20)$ : According to the manufacturer instructions, the root canals were prepared with WOG Primary (25/.07), following the creating glide path with WOGG. Both shaping and glide path instruments were used in reciprocating motion using the present program on the endodontic motor known as "WAVEONE ALL" (350 rpm, $170^{\circ}$ counterclockwise and $50^{\circ}$ clockwise) (11). The root canals were irrigated with distilled water during the instrumentation. 


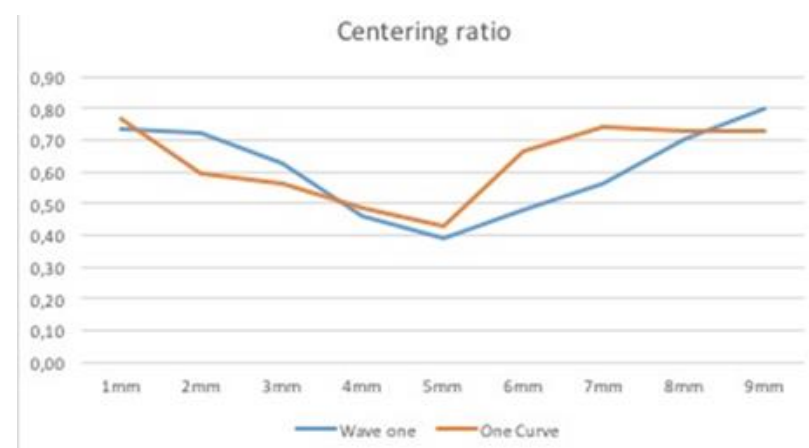

Fig. 3. Centering ratio values for WaveOne Gold and One Curve at $1 \mathrm{~mm}$ intervals

A torque-controlled endodontic motor (X Smart Plus, Dentsply Sirona, Ballaigues, Switzerland) was used in all instrumentation procedures. All the files were used only once and then discarded. The flutes of the instruments were cleaned with a gauze patch in every 3 pecks (12). All the procedures were performed by the same experienced operator who strictly observed the manufacturer instructions. This operator did not take place in the measurement steps.

The root canals were irrigated with $20 \mathrm{ml}$ distilled water as final irrigation $(13,14)$. The root canals were stained with red ink following the preparation. The post instrumentation images were taken under identical conditions.

Image analysis and evaluation of shaping ability: The pre- and post-operative images were taken by the other operator who was blind to all experimental steps. The images were superimposed using Adobe Photoshop CS5 software (Adobe Systems, Inc., San Jose, CA). Measurement scale was also prepared on superimposed images, and 9 points on each side [from the outer wall of curvature (A side) and the inner wall of curvature (B side)] of the root canal were calculated by using AutoCAD Software (Autodesk, San Rafael, CA). The measurement was made in 1-mm intervals; point 1- 3 represented the apical section, point 4-6 represented the middle section (the curvature portion of the canal), and point 7-9 represented coronal sections (the straight portion of the canal) (Figure 1). Canal transportation and centering ratio were calculated using following criteria (15):

1) The total amount of resin removal (TRR): The value obtained by combining the widths of resin removal from the 2 aspects of the canal $(A+B)$.

2) Transportation value (TV): The absolute value of the difference between the widths of resin removal from the 2 aspects of the canal $|A-B|$

3) Centering ability (CA): Calculated by dividing the narrower width of resin removal by the wider one from the 2 aspects of the canal $(\mathrm{A} / \mathrm{B})$ or $(\mathrm{B} / \mathrm{A})$.

Statistical Analysis: Statistical evaluations were performed with SPSS software (IBM SPSS Statistics 21; SPSS Inc, Chicago, IL). The normality of the variation of the data were verified using the Ryan-Joiner test (similar to Shapiro-Wilk test). Since the data does not follow the normality assumption, the Mann-Whitney $\mathrm{U}$ test was performed to analyze the data. The significance level was set at $P \leq .05$.

\section{Results}

There was no instrument separation in the study. Besides, a canal aberration occurred in OC group (Figure 2). No other procedural errors such as loss of working length, or danger zone formation were observed during the canal instrumentations.

The total amount of resin removal and transportation values: The mean values and standard deviations of total amount of resin removal and transportation values are presented in Table 1. There was no statistically significant difference among OG/OC and WOG/WOGG groups' apical (points 1-3), middle (points 4-6), or coronal (points 7-9) sections in terms of both TV and TRR. Both instruments removed more resin in the coronal, middle and apical sections of the canals, respectively.

Centering ability: The mean and standard deviation of the centering ability of groups were analyzed at 9 points from the apical constriction. The centering ability of the instruments was decreased in the curvature part (middle section) of the canals (Figure 3). There was no statistically significant difference between the two groups, except points 2, 6, and 7. While WOG group showed better centering ability at points $6-7$, OC group exhibited better results at point 2 .

\section{Discussion}

The purpose of this in vitro study was to compare the shaping ability of WOG and OC in J-shaped resin canals. Our results showed that these two systems caused similar transportation values and removed a similar amount of resin from the acrylic blocks. However, the centering ability of the systems differed by sections. The null hypothesis that there would be no difference among the shaping ability of WOG and OC in acrylic resin blocks was rejected. 
Table 1. Total amout of resin removal and transportation values for rotary systems at apical, middle and coronal sections of the resin blocks. (Std: Standart deviation, significance level was set at $P \leq .05$.)

\begin{tabular}{lcllll}
\hline & \multicolumn{2}{c}{ Transportation } & \multicolumn{2}{c}{ Total Area } & Removed \\
\hline \multirow{4}{*}{ Coronal section } & & Mean & Std. & Mean & Std. \\
& Wave one & 0.069 & 0.072 & 0.298 & 0.096 \\
& One Curve & 0.077 & 0.066 & 0.279 & 0.067 \\
& P_value & 0.203 & & 0.310 & \\
Middle section & Wave one & 0.187 & 0.093 & 0.435 & 0.098 \\
& One Curve & 0.144 & 0.06 & 0.426 & 0.058 \\
& P_value & 0.273 & & 0.588 & \\
Apical section & Wave one & 0.106 & 0.08 & 0.518 & 0.101 \\
& One Curve & 0.085 & 0.038 & 0.519 & 0046 \\
& P_value & 0.755 & & 0.343 & \\
\hline
\end{tabular}

Clinicians face several challenges during root canal treatments such as anatomical variations, damaged root canals in retreatment cases, the limits of the opening of the mouth, and patient concerns. Jshaped canals are one of the problems which may cause a big challenge for dentists. The frequency of J-shaped root canals are not rare in clinical practice and reported up to $27 \%$ in maxillary canines and $24 \%$ in mandibular central incisors (16). All systems, old or new, may cause some iatrogenic problems such as ledge formation, blocking of the canal, damaging root canal anatomy, transportations, and perforations when preparing this kind of canals which exhibits curvature and are narrow in nature (3).

There are several researches in the literature that compare the shaping ability, operation time, cyclic fatigue resistance, bacteria elimination, cutting efficiency, debris removal and instrument fracture of reciprocating systems, and continuous rotating $\mathrm{Ni}-\mathrm{Ti}$ files $(12,17-20)$. Burklein et al. compared the both shaping ability and operation time of One Shape, Reciproc, F360, and Mtwo. They showed that all tested instruments were safe to use in curvatured root canals while the operation time was less in OneShape and Reciproc than the other groups (18). Saleh et al. used 4 different single file system in S-shaped simulated root canals. Their findings showed that OneShape and F 360 showed better centering ability and less transportation values while Waveone and Reciproc systems removed more resin (12). Our results are not in accordance with that study. The main reason for this discrepancy could be this different experimental conditions. Saleh et al. did not create a glide path and used S-shaped blocks (12).
Preparing a glide path is the initial step of chemomechanical preparation (21). It helps to protect the original root canal anatomy (22). It can be created either with manual files or rotary instruments. Using a rotary glide path can prevent complications during shaping procedures in anatomically challenging canals (23). Nowadays, many rotary systems contain their glide paths. Yllmaz et al. compared the shaping ability WaveOne reciprocating files with or without glide path in S-shaped curved resin blocks. They reported that the creation of a glide path improved the centering ability of the instrument and also reduced the risk of canal aberrations (24). In the present study, the company instructions were strictly followed, and both system were used with its own glide path. Thus, it was tried to prevent shaping errors due to the anatomical difficulty created by the J-shaped canals, and it was aimed to highlight the shaping ability of the instrument itself. On the other hand, it was reported that glide path files reduced torsional stress (17). Therefore, despite the use of the Jshaped root canals in this study, the absence of any instrument separation may be due to the reduction in stress due to the smooth path created by the glide path.

In the present study, shaping efficiency evaluation was done using resin blocks. Although they do not reflect clinical conditions like human teeth in terms of hardness of dentin and cross section of the canals, they permit to standardize testing conditions of all samples regarding size, taper, and curvature (25).

Within the limitations of the study, no statistically significant difference between the rotary and 
reciprocating instruments were detected regarding the centering ability, except some tested points. One of the reasons for the lack of difference between the two groups may be related to the amount of contact between the instrument/sample surface. Similar remarks were done in Pedulla et al's study in which Hyflex EDM Glidepath file (HEGF-working in continous motion) and WOGG (working in reciprocating motion) showed similar cutting efficiency at $45^{\circ}$ and $70^{\circ}$, and greater than $90^{\circ}$ (11). On the other hand, WOG group showed better centering ability at points 6- 7 in the present study. The possible reason for this result could be the kinematic motion of the system. This file uses unequal bidirectional movement. This means that it has a net 120-degree cutting cycle of reciprocation and a complete 360 degree of rotation at the end of three cycles (3). This movement may help the instrument to stay in the center of the canal; even it has a J-shaped form.

The cutting ability of the instrument determines the fracture risk of the file, the amount of dentin removal, and the efficiency of root canal preparation. Pedulla et al. evaluated the cutting efficiency of HEGF, OG, R-pilot (RP), and WOGG. They reported that reciprocating glide path instruments (RP and WOGG) had better cutting ability than the ones working with continuous rotation (HEGF and OG) (11). In the present study, the total amount of resin removal from the canals was not affected by the kinematics of the tested systems. The reason for this difference between results may be due to the test conditions. They used the instruments in dry conditions to avoid the chemical effects of irrigation solutions (11). However, saline solution was used to lubricate the canal and decrease frictional forces in the present study (26).

Under the limitations of this study, both single-file systems were able to shape and respect the anatomy of $\mathrm{J}$ shaped canals when they were used with their own glide path files.

\section{References}

1. Yared G. Canal preparation using only one Ni-Ti rotary instrument: preliminary observations. Int Endod J 2008; 41: 339-344.

2. Letters S, Smith AJ, McHugh S, Bagg J. A study of visual and blood contamination on reprocessed endodontic files from general dental practice. $\mathrm{Br}$ Dent J 2005; 199: 522-525

3. Webber, J. Shaping canals with confidence: WaveOne GOLD single-file reciprocating system. Roots 2015; 1: 34-40.
4. Bürklein S, Schäfer E. Apically extruded debris with reciprocating single-file and full-sequence rotary instrumentation systems. Journal of endodontics 2012; 38: 850-852.

5. Staffoli S, Grande NM, Plotino G, et al. Influence of environmental temperature, heat-treatment and design on the cyclic fatigue resistance of three generations of a single-file nickel-titanium rotary instrument. Odontol 2019; 107: 301-307.

6. Micro Mega. The One Curve Brochure. Availabla at: https://micro-mega.com/wpcontent/uploads/2018/03/60301824-

D_Brochure-One-Curve-EN_WEB.pdf.

Accessed at 18.03.2020.

7. Micro Mega. The One G Brochure. Available at: https://micro-mega.com/wp-

content/uploads/2018/03/OneG_EN1_15_web. pdf. Accessed at 18.03.2020.

8. Dentsply. Wave One Gold Brochure. Available at: https://www.dentsplysirona.com/content/dam/ dentsply/pim/en_GB/Endodontics/Obturation/ Paper_Points/WaveOne_Gold_Absorbent_Point s/WaveOne\%20GOLD\%20Brochure\%202015.p df_ Accessed at 18.03.2020.

9. Vorster M, van de Vyver PJ, Paleker F. Canal Transportation and Centering Ability of WaveOne Gold in Combination with and without Different Glide Path Techniques. J Endod 2018; 44: 1430-1435.

10. Dhingra A, Kochar R, Banerjee S, Srivastava P. Comparative evaluation of the canal curvature modifications after instrumentation with One Shape rotary and Wave One reciprocating files. J Conserv Dent 2014; 17: 138

11. Pedulla E, Leanza G, La Rosa GRM, et al. Cutting efficiency of conventional and heat- treated nickel-titanium rotary or reciprocating glide path instruments. Int Endod J 2020; 53: 376-384.

12. Saleh AM, Gilani PV, Tavanafar S, Schafer E. Shaping Ability of 4 Different Single-file Systems in Simulated S-shaped Canals. J Endod 2015; 41: 548-552.

13. Özyürek T, Yilmaz K, Uslu G. Shaping ability of Reciproc, WaveOne GOLD, and HyFlex EDM single-file systems in simulated S-shaped canals. J Endod 2017;43: 805-809.

14. Ates AA, Arıcan B, Işık V. Comparison of Shaping Ability of XP-Endo Shaper in Simulated J-Shaped Canals with Various Sizes. Journal of Research in Medical and Dental Science 2020; 8: 176-181.

15. Ersev H, Yilmaz B, Ciftçioğlu E, ÖzkarsII SF. A comparison of the shaping effets of 5 nickeltitanium rotary instruments in simulated S-shaped canals. Oral Surg Oral Med Oral Pathol Oral Radiol Endod 2010; 109: 86-93.

16. Beshkenadze E, Chipashvili N. Anatomomorphological features of the root canal system in Georgian population-cone-beam computed tomography study. Georgian Med News 2015; 247: 7-14. 
17. Di Giuseppe I, Di Giuseppe D, Malagnino VA, Silla EP, Somma F. Conditioning of root canal anatomy on static and dynamics of nickel-titanium rotary instruments. Giornale Italiano di Endodonzia 2015; 29: 58-64.

18. Burklein S, Hinschitza K, Dammaschke T, Schafer E. Shaping ability and cleaning effectiveness of two single-file systems in severely curved root canals of extracted teeth: Reciproc and WaveOne versus Mtwo and ProTaper. Int Endod J 2012; 45: 449-641.

19. Türker SA, Koçak S, Kocak M, Saglam B. Effect of glide path preparation on apical debris extrusion of rotary and reciprocating single-file systems: OneShape versus WaveOne. Cumhuriyet Dent J 2015; 18: 1-8.

20. Bürklein S, Benten S, Schäfer E. Shaping ability of different single-file systems in severely curved root canals of extracted teeth. Int Endod J 2013; 46: 590-597.

21. Alovisi M, Cemenasco A, Mancini L, et al. MicroCT evaluation of several glide path techniques and ProTaper Next shaping outcomes in maxillary first molar curved canals. Int Endod J 2017; 50: 387-397.
22. You S-Y, Kim H-C, Bae K-S, Baek SH, Kum KY, Lee W. Shaping ability of reciprocating motion in curved root canals: a comparative study with micro-computed tomography. J Endod 2011; 37: 1296-1300.

23. Ha J-H, Park S-S. Influence of glide path on the screw-in effect and torque of nickel-titanium rotary files in simulated resin root canals. Restor Dent Endod 2012; 37: 215.

24. Yilmaz A, Kucukay ES, Istektepe M, Sisli SN, Ersev H, Karagoz-Kucukay I. Comparison of the shaping ability of WaveOne Reciprocating files with or without glide path in simulated curved Sshaped root canals. J Int Soc Prev Community Dent 2017; 7: 13.

25. Muñoz E, Forner L, Llena C. Influence of operator's experience on root canal shaping ability with a rotary nickel-titanium single-file reciprocating motion system. J Endod 2014; 40: 547-550.

26. Shen Y, Haapasalo M. Three-dimensional analysis of cutting behavior of nickel-titanium rotary instruments by microcomputed tomography. J Endod 2008; 34: 606-610 